\title{
The Effect of Microstructure Morphology on Indentation Response of Ta/Ti Nanocomposite Thin Films
}

\author{
IAN MCCUE, SISI XIANG, KELVIN XIE, and MICHAEL J. DEMKOWICZ
}

\begin{abstract}
We investigated the indentation response of $\mathrm{Ta} / \mathrm{Ti}$ nanocomposite thin films with widely differing morphologies of the constituent phases, ranging from particulate to bicontinuously interpenetrating, but comparable characteristic dimensions of microstructure features. We find no influence of microstructure morphology on stiffness or hardness. However, we see a systematic dependence of indentation pileup height on microstructure morphology, with the largest pileups observed in composites with connected, Ta-rich networks and lowest for highly connected, Ti-rich networks. We attribute this dependence to an influence of microstructure morphology on strain hardening rates and propose mechanisms to explain it.
\end{abstract}

https://doi.org/10.1007/s11661-020-05969-w

(c) The Minerals, Metals \& Materials Society and ASM International 2020

\section{INTRODUCTION}

NANO-METALLIC materials (NMMs) - polycrystalline, porous, and composite metals with microstructural features below $100 \mathrm{~nm}$ - have been the subject of intensive research over the past decades. ${ }^{[1-5]}$ This research has been driven largely by a desire to elucidate the effect of characteristic microstructure dimensions ${ }^{[6]}$ and interface (or surface) area-to-volume $\operatorname{ratios}^{[7]}$ on materials properties such as mechanical, ${ }^{[8-10]}$ radiation response, ${ }^{[11,12]}$ and electrochemical actuation. ${ }^{[13,14]}$ However, the effect of microstructure morphology-i.e., the shape, orientation, and connectivity of microstructure elements - on these properties has not been investigated in comparable detail. ${ }^{15]}$

In this study, we investigate the effect of microstructure morphology on the mechanical properties of $\mathrm{Ta} / \mathrm{Ti}$ nanocomposites, as characterized via nanoindentation. Thin films of these materials are synthesized by heat treating $\mathrm{Ta}_{x} \mathrm{Ti}_{1-x}$ solid solutions vapor deposited by magnetron sputtering. ${ }^{[16]}$ By changing initial alloy compositions and processing routes (times and temperatures of heat treatment), we synthesize nanocomposites with comparable characteristic dimensions of microstructure

IAN MCCUE is with the Department of Materials Science and Engineering, Texas A\&M University, College Station, TX 77840 and also with the Research and Exploratory Development Department, Johns Hopkins University Applied Physics Laboratory, Laurel, MD 20723. Contact e-mail: ian.mccue@jhuapl.edu SISI XIANG, KELVIN XIE and MICHAEL J. DEMKOWICZ are with the Department of Materials Science and Engineering, Texas A\&M University.

Manuscript submitted March 22, 2020.

Article published online September 3, 2020 features, but widely differing microstructure morphologies, ranging from particulate to interpenetrating bicontinuous.

Despite these differences, all of the nanocomposites exhibit comparable enhancements in hardness over the original thin film and individual elemental constituents. However, microstructure morphology has a marked effect on indentation pileup height: pileups are largest for composites with connected, Ta networks and non-percolating $\mathrm{Ti}$ particles and lowest for highly connected, Ti networks and non-percolating Ta particles. Comparison of the as-synthesized and deformed microstructures leads us to hypothesize that these differences in pileup height are due to a marked influence of microstructure morphology on composite straining hardening behavior. Potential mechanisms of strain hardening in these materials are proposed. Our work suggests that strain hardening - and therefore flow uniformity - in NMMs may be tuned by altering their microstructure morphology without affecting strength.

\section{EXPERIMENTAL METHODS}

\section{A. Synthesis and Characterization of Thin-Film Samples}

TaTi thin films were prepared by DC Magnetron co-sputtering Ta and Ti targets on 1-mm-thick, $2 \times 2$ inch $^{2}$ polycrystalline $\mathrm{Zr}$ substrates using the ATC Orion Series Sputtering System at the Center for Integrated Nanotechnologies (CINT) at Los Alamos National Laboratory. The $\mathrm{Zr}$ substrates $(99.2 \mathrm{wt} \mathrm{pct}$ ) were cut from a 1-mm-thick $100 \times 100 \mathrm{~mm}^{2}$ sheet (Alfa Aesar) and polished to a mirror finish. All substrates were cleaned with $\mathrm{O}_{2}$ plasma for 15 minutes prior to 
deposition to remove any surface impurities. The TiTa/ $\mathrm{Zr}$ alloy system was also used in a previous study on solid metal dealloying. ${ }^{[16]}$

Deposition was carried out at $500{ }^{\circ} \mathrm{C}$ to ensure compositional homogeneity at a deposition rate of 0.25 $\mathrm{nm} / \mathrm{s}$ to a final film thickness of $500 \mathrm{~nm}$. The elevated deposition temperature leads to a coarser grain size $(\sim 300 \mathrm{~nm})$ than room temperature deposition, but ensures chemical homogeneity and a uniform TaTi BCC solid solution. Four different $\mathrm{Ta}_{x} \mathrm{Ti}_{1-x}$ compositions were prepared: $\mathrm{Ta}_{15} \mathrm{Ti}_{85}, \mathrm{Ta}_{25} \mathrm{Ti}_{75}, \mathrm{Ta}_{35} \mathrm{Ti}_{65}$, and $\mathrm{Ta}_{45} \mathrm{Ti}_{55}$. After deposition, the film surfaces were characterized using scanning electron microscopy (SEM) and electron dispersive spectroscopy (EDS).

Thin-film samples for heat treatment were prepared by cutting $4 \times 4 \mathrm{~mm}^{2}$ squares out of the deposited films using wire electric discharge machining. Prior to heat treatment in a muffle furnace, the $4 \times 4 \mathrm{~mm}^{2}$ square samples were individually sealed in quartz tubes under $5 \times 10^{-6}$ torr, back-filling with ultra-high purity $\operatorname{Ar}$ (99.995 wt pet). Three heat treatments were used in this study: $500{ }^{\circ} \mathrm{C} 162$ hours, $550{ }^{\circ} \mathrm{C} 10$ hours, and $550{ }^{\circ} \mathrm{C} 162$ hours. All three treatments were applied to each of the four aforementioned film compositions, yielding twelve sample types, each with a distinct composition/processing combination.

To remove any surface oxides and lightly polish the surface, heat-treated samples underwent 12 hours of vibratory polishing with $50 \mathrm{~nm}$ colloidal silica in a Buehler Vibromat. This process removed $\sim 50 \mathrm{~nm}$ from the film surface. The samples were characterized by combining focused ion beam milling (FIB) and SEM. Secondary electron SEM was performed using a Tescan FERA-3 instrument. EDS measurements were performed on the film surface using an Oxford X-MaxN detector. Ion beam milling was performed using a Tescan LYRA-3 with a Canion Ga LMIS FIB column.

To image the microstructure below the sample surface, $20-\mu \mathrm{m}$-wide cross sections of the heat-treated films were prepared by trench milling at $30 \mathrm{kV}$ and $10 \mathrm{nA}$, and polishing steps of 5, 3, 1, and $700 \mathrm{pA}$ at $30 \mathrm{kV}$. Images of the microstructures observed in this study were analyzed using a custom segmentation and measurement software called AQUAMI. ${ }^{[1]}$ AQUAMI analyzes each pixel in an image and outputs microstructural features such as the area fraction of each phase and the full distributions of feature dimensions. A complete description of AQUAMI may be found in Reference 17.

Bright-field transmission electron microscopy (TEM), high-angle annular dark-field scanning TEM (HAADF-STEM), and EDS were performed on selected specimens using the FEI Tecnai G2 F20 Super-Twin FE-TEM with an EDAX detector operating at $200 \mathrm{kV}$. Samples $(\sim 90 \mathrm{~nm}$ thick) were prepared via the standard FIB lift-out technique, undergoing individual steps of $\mathrm{Pt}$ deposition, trench milling, lift-out via a $\mathrm{W}$ needle, mounting to a $\mathrm{Cu}$ grid, thinning, and cleaning. ${ }^{[18]}$

\section{B. Indentation Testing}

We performed continuous stiffness indentation measurements using a Nanomechanics iNano indenter with new tips from Micro Star Technologies. These measurements allowed us to probe indentation modulus and hardness as a function of indentation depth. Tests were performed on all twelve sample types mentioned in the previous section as well as on three reference samples: pure $\mathrm{Ti}$, pure $\mathrm{Ta}$, and a representative as-deposited (not heat treated) $\mathrm{Ta}_{35} \mathrm{Ti}_{65}$ film. Nine independent tests were conducted at different locations on each sample. Additionally, we also conducted indentations under monotonic loading to depths of 50 and $100 \mathrm{~nm}$ using a Hysitron Ti 950 triboindenter. Sixteen tests were performed on each of the above-mentioned samples. We used a Berkovich indenter (with a $20 \mathrm{~nm}$ radius measured by the manufacturer) for all these tests because it probes a representative volume of material while maintaining a shallow indentation depth.

In addition to modulus and hardness, we also characterized the indentation pileup behavior of the heat-treated films and three reference samples. For these tests, we used a single cube-corner indenter (with a 20 $\mathrm{nm}$ radius measured by the manufacturer) because their steeper tip angles give rise to larger maximum plastic strain under the indent than do Berkovich tips: $\sim 22$ pct for the former compared to $\sim 7$ pct for the latter. ${ }^{[19]}$ The amount of pileup around the indent is dependent on this strain, leading to larger pileups for indenters with steeper tip angles. ${ }^{[20,21]}$ Thus, cube corners give larger pileups that are more easily distinguished from the roughness of the film surface.

We conducted ten cube-corner indentation tests per sample using a monotonic load function to a depth of $200 \mathrm{~nm}$ using a Hysitron Ti 950 triboindenter. After indentation, the sample surface topography was measured with a Hysitron $\mathrm{Ti} 950$ triboindenter at a tip velocity of $2 \mu \mathrm{m} / \mathrm{s}$ and a step size of $40 \mathrm{~nm}$. Line profiles of surface height were extracted across the indents and the maximum pileup height along each profile was determined. Three profiles were extracted from each indent - one through each of the corners - for a total of thirty line profiles per sample.

\section{MICROSTRUCTURE IN HEAT-TREATED $\mathrm{Ta}_{x} \mathrm{Ti}_{1-x}$ FILMS}

Figure 1 shows secondary electron images of a $\mathrm{Ta}_{35} \mathrm{Ti}_{65}$ film before and after heat treatment at $550{ }^{\circ} \mathrm{C}$ for 162 hours. We used the GIMP software ${ }^{[22]}$ to combine surface and cross-section images into perspective views of the film microstructure. The as-deposited $\sim 500$-nm-thick film appears uniform. Upon heat treatment, it transforms into a two-phase composite consisting of a Ta-rich phase (the brighter component) and a Ti-rich phase (darker component). These microstructures are qualitatively distinct from the martensitic microstructures found in bulk homogenized and quenched Ta-Ti alloys. ${ }^{[23,24]}$ Specifically, the Ti-rich phases in the thin films do not take the form of discrete needles, as in the bulk alloys. Rather, they are extensively interconnected with each other. Moreover, their interfaces with the adjoining Ta-rich phases are highly curved. 


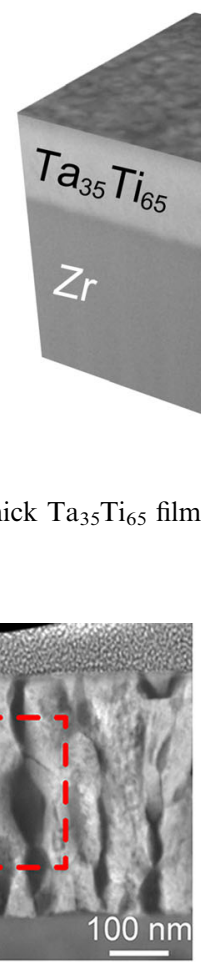

(a)

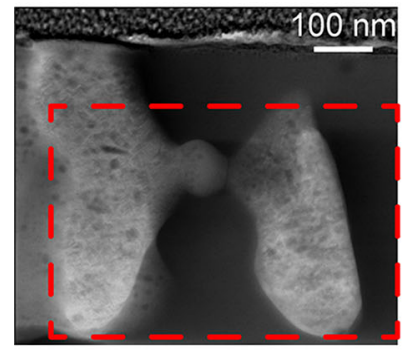

(e)

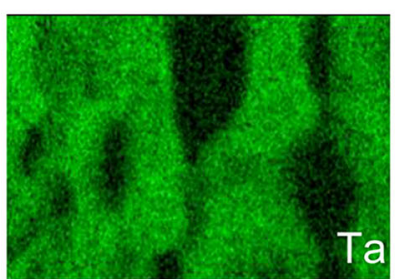

(b)

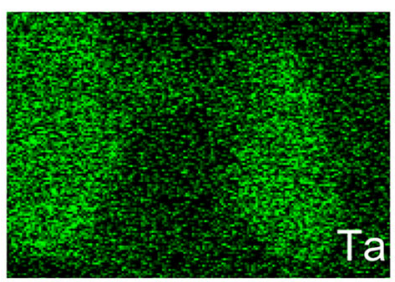

(f)

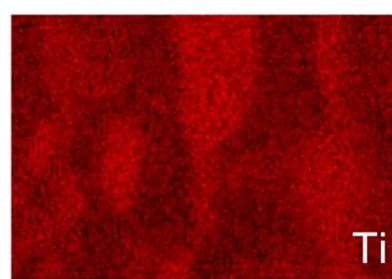

(c)

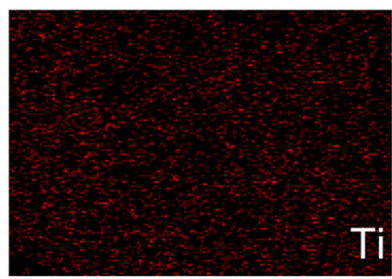

(g)

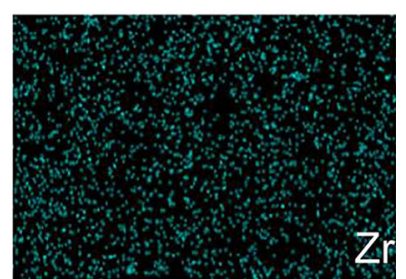

(d)

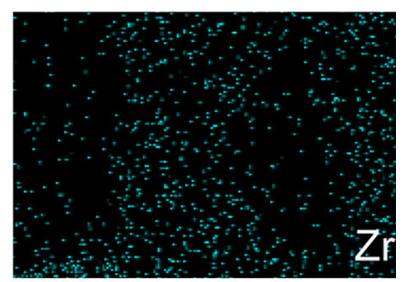

(h)

Fig. 2- Ta/Ti composites synthesized from $\mathrm{Ta}_{35} \mathrm{Ti}_{65}$ parent alloy processed at $550{ }^{\circ} \mathrm{C}$ for $(a)$ through $(d) 10 \mathrm{~h}$, and $(e)$ through $(h) 162 \mathrm{~h}$. In both cases, the TaTi alloy phase separates into (b) and (f) Ta-rich (bright/green) and (c) and (g) Ti-rich (dark/red) phases. At longer processing times, the structure is coarser than at shorter processing times. Both samples appear to contain a uniform distribution of (d) and (h) Zr impurities, albeit at much higher concentration after longer heat treatments (see Table I) (Color figure online).

We attribute the above-mentioned differences in microstructure to the constrained dimensions of the thin film as well as interdiffusion with the $\mathrm{Zr}$ substrate during heat treatment. We quantified the chemical composition of the individual phases in the thin films by performing TEM and EDS analysis on the sample shown in Figure 1 as well as a $\mathrm{Ta}_{35} \mathrm{Ti}_{65}$ sample heat treated at $550{ }^{\circ} \mathrm{C}$ for 10 hours. The EDS maps in Figure 2 confirm that each constituent phase in the films contains appreciable fractions of $\mathrm{Zr}$. These $\mathrm{Zr}$ impurities may play an important role in morphology formation during phase separation of the initially uniform $\mathrm{Ta}-\mathrm{Ti}$ alloy films. Table I reports the compositions and area fractions of both phases analyzed in the thin-film samples in Figure 2.

Investigating all twelve samples types described in Section II-A, we observe three distinct classes of microstructures based on connectivity, as illustrated in
Figure 3. Figure 3(a) shows a sample with fully connected Ta-rich matrix containing discrete Ti-rich particles embedded within it (labeled as microstructure connectivity type $\alpha$ ). The composite in Figure 3(b) also has a fully connected Ta-rich matrix, but with the Ti-rich phase forming long, rod-like particles oriented perpendicular to the sample surface (labeled as microstructure connectivity type $\beta$ ). The composite in Figure 3(c) appears to be bicontinuous, ${ }^{[25,}{ }^{26]}$ with both Ta- and Ti-rich phases interconnected into unbroken, system-spanning networks (labeled as microstructure connectivity type $\gamma$ ). Finally, the composite in Figure 3(d) consists of a Ti-rich matrix containing Ta-rich particles (labeled as microstructure connectivity type $\delta$ ).

Table II reports microstructure connectivity as well as mean feature sizes and Ta-rich phase fractions for all twelve thin-film samples investigated here. Top-surface 
Table I. Composition and Area Fraction of Ta-Rich and Ti-Rich Phases in Heat-Treated Films Shown in Fig. 2

Heat Treatment Mean Composition of Ta-Rich Phase (At Mean Composition of Ti-Rich Phase (At Area Fraction of Time (h) Pct Ta/Ti/Zr)

$\mathrm{Pct} \mathrm{Ta} / \mathrm{Ti} / \mathrm{Zr})$

\begin{tabular}{llll}
\hline 10 & $45.58 / 51.35 / 3.07$ & $7.64 / 88.84 / 3.52$ & 0.747 \\
162 & $67.40 / 29.62 / 2.98$ & $25.37 / 35.95 / 38.68$ & 0.536 \\
\hline
\end{tabular}

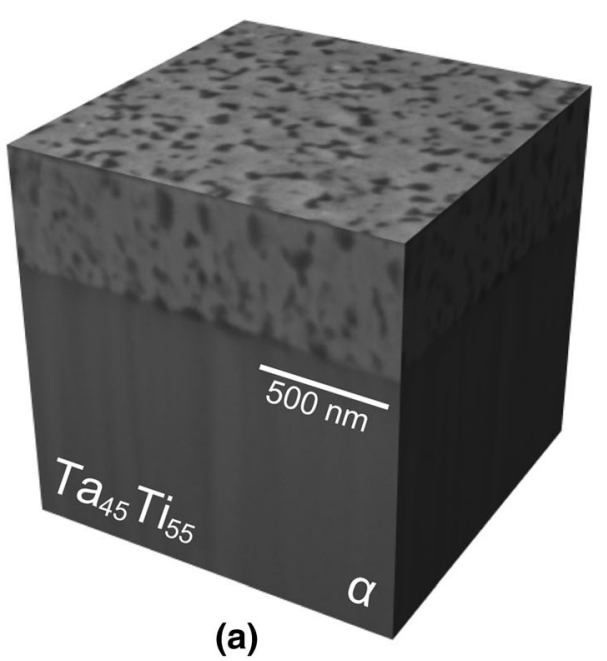

(a)

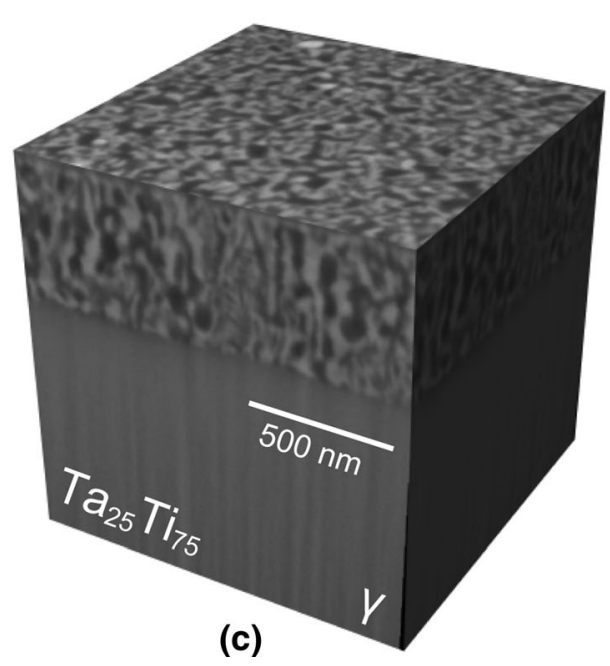

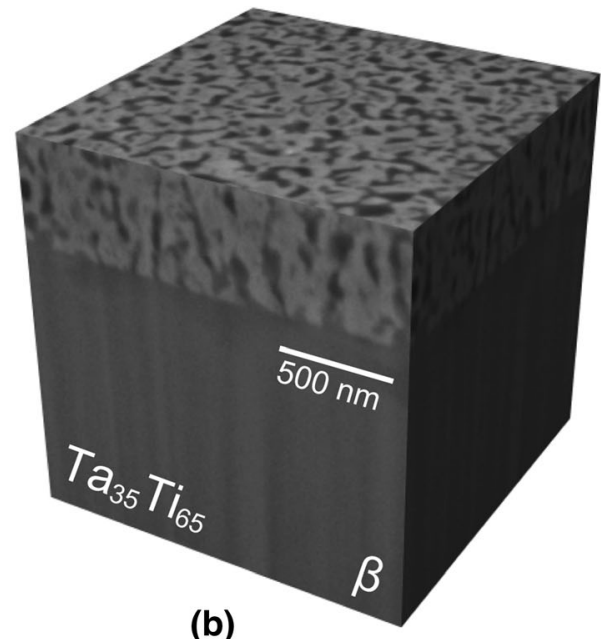

(b)

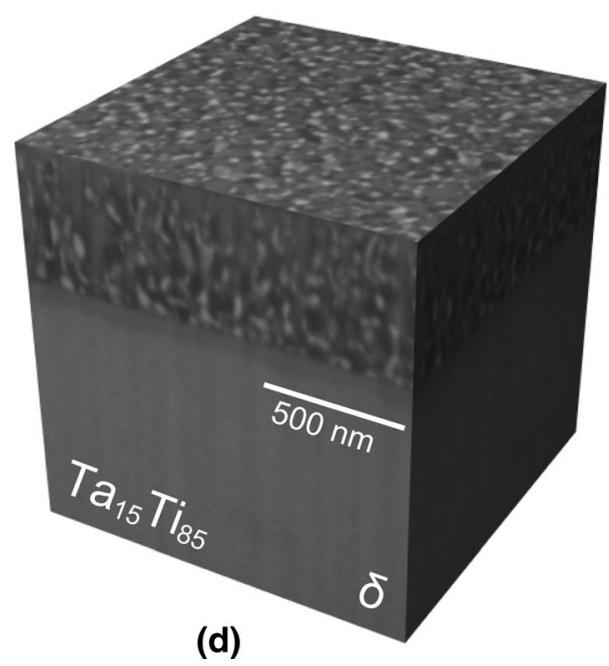

Fig. 3- $\mathrm{Ta} / \mathrm{Ti}$ composites of differing as-deposited alloy compositions processed at $500{ }^{\circ} \mathrm{C}$ and $10 \mathrm{~h}$. As the Ta content increases, so does the connectivity of the Ta-rich (brighter) phase: $(a) \mathrm{Ti}_{55} \mathrm{Ta}_{45}$ forms an interconnected $\mathrm{Ta}$ network with non-percolating $\mathrm{Ti}_{1}$ particles, $(b) \mathrm{Ti}_{65} \mathrm{Ta}_{35}$ forms an interconnected $\mathrm{Ta}$ network with non-percolating Ti-rich rods aligned perpendicular to the sample surface, (c) $\mathrm{Ti}_{75} \mathrm{Ta}_{25}$ with interpenetrating $\mathrm{Ta}$ - and Ti-rich phases, and $(d) \mathrm{Ti}_{55} \mathrm{Ta}_{45}$ composite with interconnected Ti-rich network and non-percolating Ta-rich particles. Greek symbols within each subfigure are used to identify different microstructure connectivity types between samples.

images of the heat-treated films reveal approximately isotropic distributions Ta- and Ti-rich phases, while cross-sectional view show elongated Ta-rich filaments with long axes preferentially oriented perpendicular to the sample surface. Therefore, in Table II, we report data for both surface and cross-section images independently. On the whole, Ta-rich features are larger in cross sections than in plan view, though feature dimensions have wide distributions in both types of images.
Of all the parameters varied during processing, we find that the as-deposited alloy composition has the greatest influence on the microstructure morphology of our composites: changing the processing temperature and time while keeping alloy composition fixed results in qualitatively similar morphologies. The area fraction of the Ta-rich phase in the composites is well correlated with the Ta content of the as-deposited alloy, as illustrated in Figure 4, though there is substantial spread 
Table II. Ta-Rich Phase Fractions, Average Feature Sizes, and Microstructure Connectivity for Heat-Treated Ta/Ti Composites

\begin{tabular}{|c|c|c|c|c|c|c|c|}
\hline \multirow[b]{2}{*}{$\begin{array}{l}\text { Ta Fraction of Parent Alloy } \\
\text { (At Pct) }\end{array}$} & \multirow[b]{2}{*}{$\begin{array}{l}\text { Treatment } \\
\text { ture }\left({ }^{\circ} \mathrm{C}\right)\end{array}$} & \multirow[b]{2}{*}{$\begin{array}{l}\text { Treatment } \\
\text { Time }(\mathrm{h})\end{array}$} & \multicolumn{2}{|c|}{$\begin{array}{l}\text { Feature Size: Mean } \\
\pm \text { Standard Devia- } \\
\text { tion }(\mathrm{nm})\end{array}$} & \multicolumn{2}{|c|}{$\begin{array}{l}\text { Ta-Rich Area } \\
\text { Fraction }\end{array}$} & \multirow[b]{2}{*}{$\begin{array}{l}\text { Connectivity } \\
\text { Type }\end{array}$} \\
\hline & & & $\begin{array}{l}\text { Plan } \\
\text { View }\end{array}$ & $\begin{array}{l}\text { Cross } \\
\text { Section }\end{array}$ & $\begin{array}{l}\text { Plan } \\
\text { View }\end{array}$ & $\begin{array}{l}\text { Cross } \\
\text { Section }\end{array}$ & \\
\hline 45 & 500 & 162 & $23 \pm 9$ & $44 \pm 21$ & 0.7 & 0.76 & $\alpha$ \\
\hline 45 & 550 & 10 & $56 \pm 21$ & $73 \pm 29$ & 0.67 & 0.72 & $\alpha$ \\
\hline 45 & 550 & 162 & $70 \pm 30$ & $75 \pm 33$ & 0.65 & 0.7 & $\alpha$ \\
\hline 35 & 500 & 162 & $42 \pm 17$ & $32 \pm 12$ & 0.64 & 0.53 & $\beta$ \\
\hline 35 & 550 & 10 & $41 \pm 19$ & $50 \pm 17$ & 0.58 & 0.61 & $\beta$ \\
\hline 35 & 550 & 162 & $89 \pm 32$ & $116 \pm 36$ & 0.45 & 0.42 & $\beta$ \\
\hline 25 & 500 & 162 & $20 \pm 7$ & $36 \pm 7$ & 0.52 & 0.5 & $\gamma$ \\
\hline 25 & 550 & 10 & $43 \pm 18$ & $40 \pm 13$ & 0.51 & 0.52 & $\gamma$ \\
\hline 25 & 550 & 162 & $42 \pm 14$ & $53 \pm 22$ & 0.47 & 0.48 & $\dot{\gamma}$ \\
\hline 15 & 500 & 162 & $33 \pm 13$ & $38 \pm 11$ & 0.29 & 0.18 & $\delta$ \\
\hline 15 & 550 & 10 & $40 \pm 13$ & $28 \pm 8$ & 0.26 & 0.24 & $\delta$ \\
\hline 15 & 550 & 162 & $50 \pm 15$ & $47 \pm 17$ & 0.26 & 0.25 & $\delta$ \\
\hline
\end{tabular}

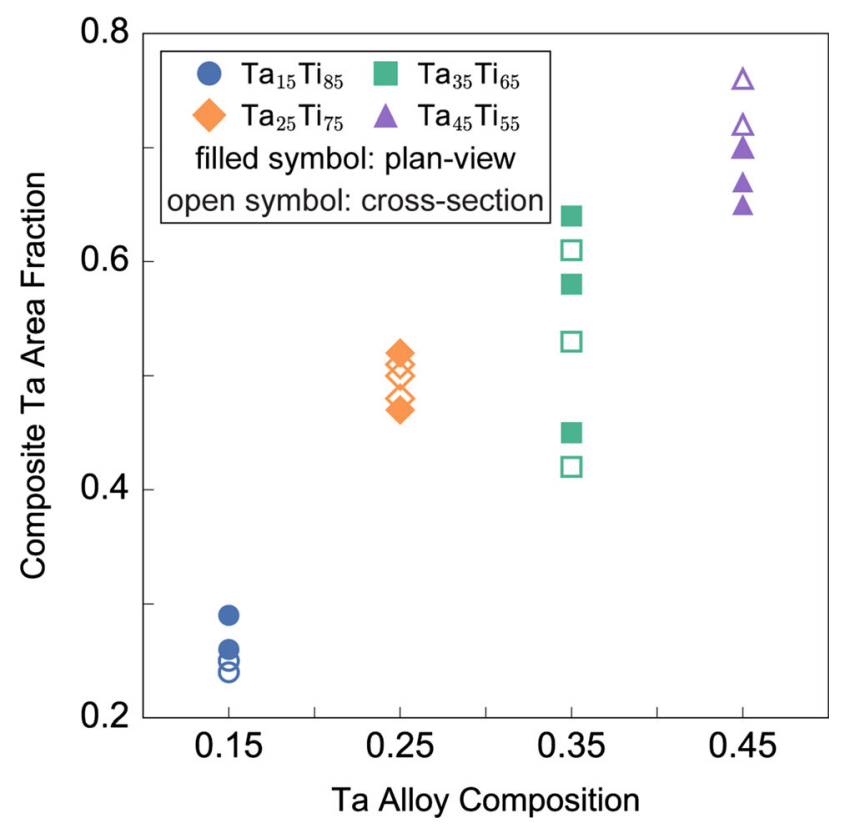

Fig. 4-Area fraction of the Ta-rich phase plotted against the composition in the as-deposited alloy. Filled symbols indicate data from plan-view images and open symbols from cross sections.

in the Ta-rich phase fraction even for samples with identical parent composition. We did not find any correlation between the fraction of Ta-rich phase and heat treatment time or temperature, indicating that there are additional factors (such as nucleation processes during the initial stages of phase separation) contributing to the development of microstructure morphology in these materials.

The average feature size of all the films lies in the 20 to $90 \mathrm{~nm}$ range, demonstrating that all of these films may be considered nanocomposite materials. Feature sizes appeared to be best correlated to the treatment temperature, as shown in Figure 5(a), and-to a lesser extent - to the time, Figure 5(b). As in other NMMs, ${ }^{[27]}$ these correlations likely arise from the temperature- and time-dependence of coarsening during processing, which is governed by the mobility of the phase separating elements. The greater scatter in the dependence of composite features size on time may be due to variations in microstructure connectivity, which are thought to affect coarsening exponents. ${ }^{28,29]}$

\section{INDENTATION RESPONSE OF NANOCOMPOSITES}

The variety of microstructure types, feature sizes, and phase fractions exhibited by the Ta-Ti nanocomposites create an opportunity to investigate the effect of microstructure morphology on mechanical response. We use nanoindentation to assess the dependence of hardness, modulus, and pileup behavior on the microstructure parameters reported in Table II.

\section{A. Hardness and Modulus}

Figure 6 presents representative indentation depth dependence of the elastic modulus and hardness for the four representative $\mathrm{Ta} / \mathrm{Ti}$ composites in Figure 3. All other indentation data acquired in continuous stiffness mode are qualitatively similar to these four profiles: they exhibit a rise in modulus with indentation depth near the surface, a plateau in elastic modulus for depths between 50 and $150 \mathrm{~nm}$ (corresponding to 10 to 35 pct of the film thickness), and a linear decrease in modulus for depths greater than $\sim 150 \mathrm{~nm}$. The linear decrease is due to rising influence at increasing indentation depths of the $\mathrm{Zr}$ substrate, which is more compliant than the nanocomposite film. This trend is consistent with the model for substrate effects developed by Gao et al. ${ }^{[30]}$ and Hay and Crawford. ${ }^{[31]}$ Following the work by $\mathrm{Li}$ and Vlassak, ${ }^{[32]}$ we expect minimal substrate effects given the similarities in elastic moduli between the film 


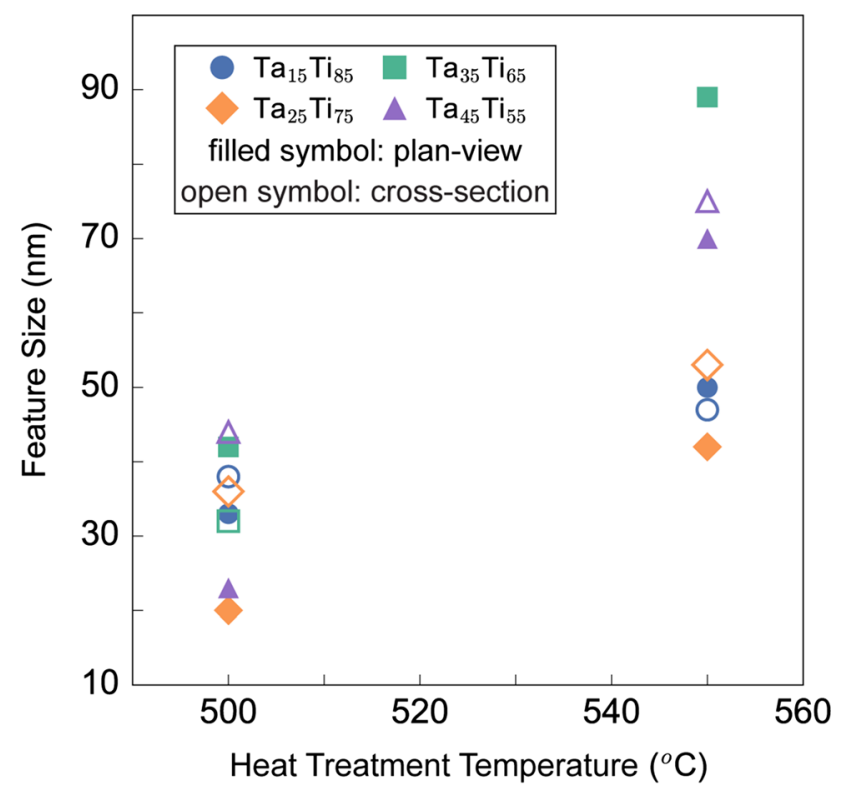

(a)

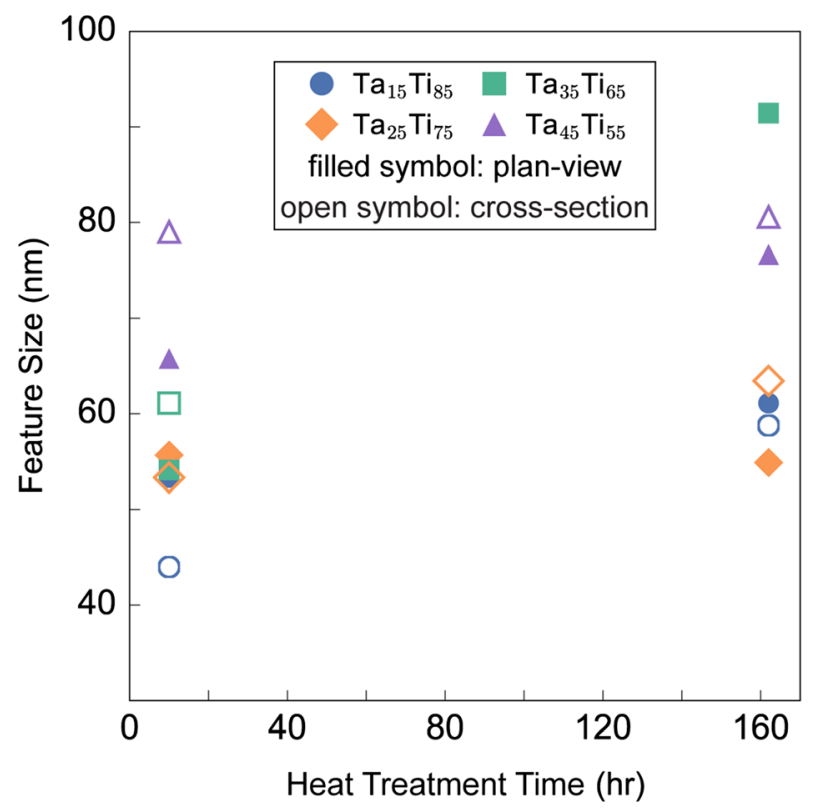

(b)

Fig. 5-Dependence of average feature size on heat treatment $(a)$ temperature and (b) time. Filled symbols indicate data from plan-view images and open symbols from cross sections.

and substrate. Therefore, the most reliable determination of the modulus of the film may be obtained from indents with a depth in the 50 to $150 \mathrm{~nm}$ range.

The qualitative trends in Figure 6(a) at low indentation depths are in good agreement for bulk TiTa composite estimates using Hashin-Shtrikman bounds. ${ }^{[33]}$ Using the area fractions of the Ta-rich and Ti-rich phases (from Table II) and hardness values (estimated using the phase fractions in Figure 1), the elastic moduli for bulk TiTa nanocomposites fall between 127 and $140 \mathrm{GPa}$. This range of elastic moduli values is slightly higher than our measurements in

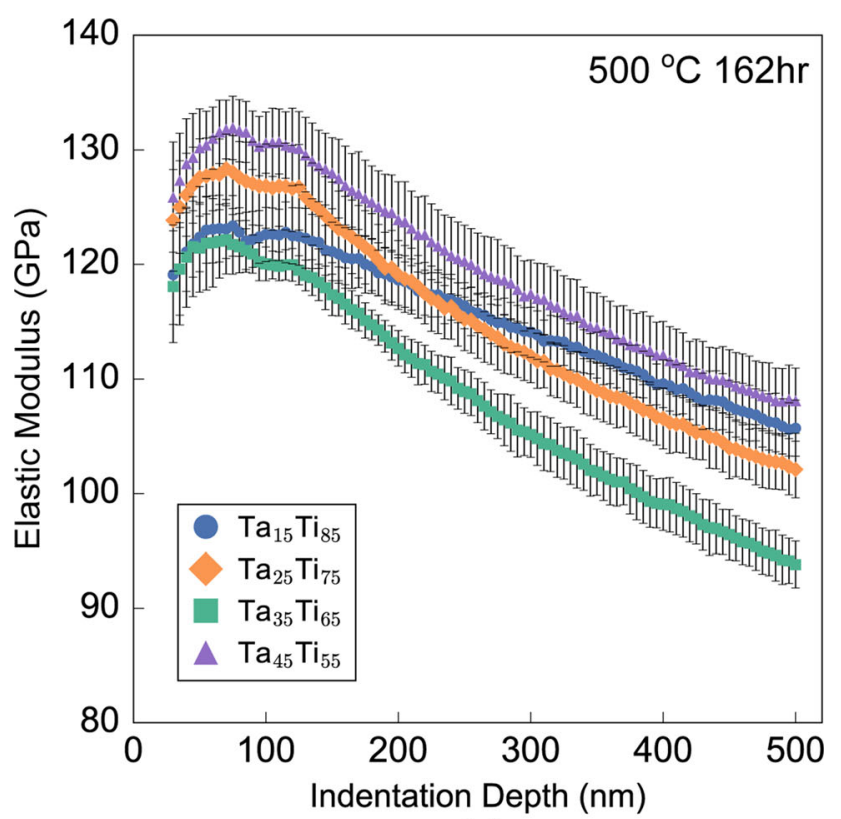

(a)

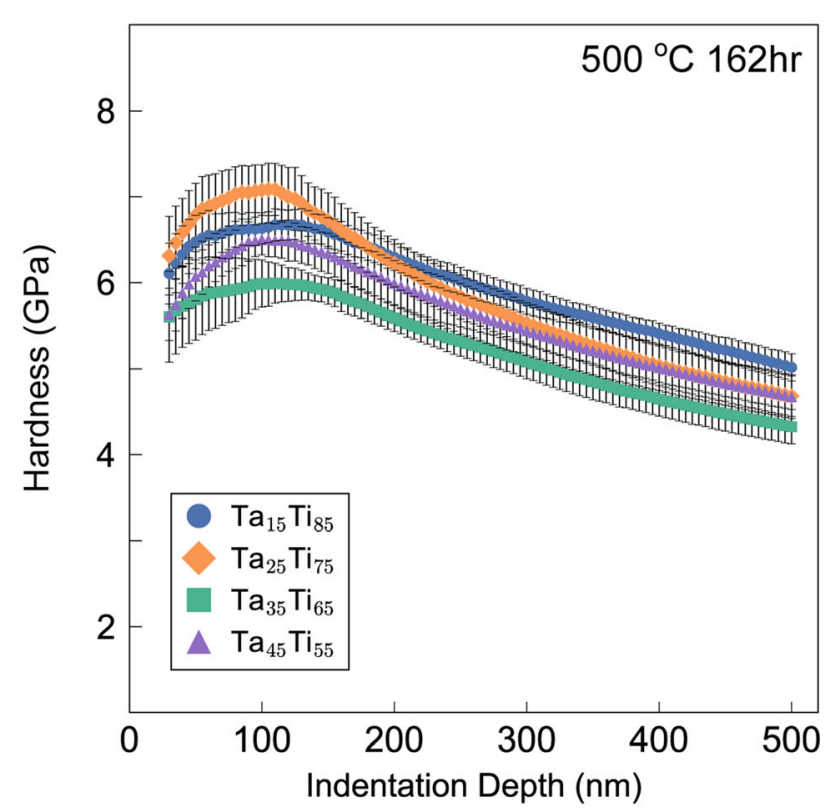

(b)

Fig. 6-Indentation depth dependence of ( $a$ ) elastic modulus and (b) hardness obtained using continuous stiffness mode measurements for the four representative films shown in Fig. 3. All of our other measurements were qualitatively similar to these. For each sample, the elastic modulus and hardness exhibits a plateau at depths between 50 and $150 \mathrm{~nm}$ followed by a linear decrease at greater depths due to the increasing influence of the $\mathrm{Zr}$ substrate.

Figure 6(a) ( 122 to $132 \mathrm{GPa})$ and is likely due to the impact of the $\mathrm{Zr}$ substrate. However, this error is in the range of 4 to 6 pct, which is quite small and indicates a minimal substrate effect at shallow depths.

Similar to elastic modulus, all of the samples exhibit a plateau in the hardness for indentation depths of 50 to $150 \mathrm{~nm}$ (corresponding to 10 to $35 \mathrm{pct}$ of the film thickness). After $\sim 150 \mathrm{~nm}$ the hardness has a nearly 
Table III. Indentation Modulus, Hardness, and Pileup Height for Ta/Ti Nanocomposites, an As-Deposited Ta ${ }_{35}$ Ti 65 Film, Pure Ti, and Pure Ta

\begin{tabular}{|c|c|c|c|c|c|c|c|}
\hline $\begin{array}{l}\text { Ta Fraction of } \\
\text { Alloy (At Pct) }\end{array}$ & $\begin{array}{l}\text { Treatment } \\
\text { Time (h) }\end{array}$ & $\begin{array}{l}\text { Treatment } \\
\text { Temperature } \\
\quad\left({ }^{\circ} \mathrm{C}\right)\end{array}$ & $\begin{array}{l}\text { Hardness at } \\
50 \mathrm{~nm}(\mathrm{GPa})\end{array}$ & $\begin{array}{c}\text { Modulus at } 50 \\
\mathrm{~nm}(\mathrm{GPa})\end{array}$ & $\begin{array}{l}\text { Hardness at } \\
100 \mathrm{~nm}(\mathrm{GPa})\end{array}$ & $\begin{array}{l}\text { Modulus at } \\
100 \mathrm{~nm}(\mathrm{GPa})\end{array}$ & $\begin{array}{l}\text { Pileup } \\
\text { Height } \\
(\mathrm{nm})\end{array}$ \\
\hline 15 & 500 & 162 & $7.60 \pm 0.20$ & $133 \pm 4$ & $8.1 \pm 0.44$ & $139 \pm 9$ & $28.6 \pm 5.5$ \\
\hline 15 & 550 & 10 & $7.47 \pm 0.90$ & $130 \pm 10$ & $7.52 \pm 0.75$ & $128 \pm 7$ & $26.3 \pm 2.5$ \\
\hline 15 & 550 & 162 & $6.41 \pm 0.78$ & $117 \pm 12$ & $6.38 \pm 0.81$ & $117 \pm 10$ & $21.8 \pm 5.6$ \\
\hline 25 & 500 & 162 & $7.68 \pm 0.52$ & $138 \pm 8$ & $7.66 \pm 0.3$ & $131 \pm 4$ & $35.9 \pm 4.3$ \\
\hline 25 & 550 & 10 & $6.95 \pm 0.76$ & $151 \pm 14$ & $7.19 \pm 0.6$ & $138 \pm 9$ & $34.7 \pm 3$ \\
\hline 25 & 550 & 162 & $6.45 \pm 0.32$ & $130 \pm 5$ & $6.16 \pm 0.25$ & $122 \pm 4$ & $35.2 \pm 3.2$ \\
\hline 35 & 500 & 162 & $6.28 \pm 1.01$ & $128 \pm 14$ & $6.38 \pm 1.03$ & $129 \pm 10$ & $49 \pm 7.4$ \\
\hline 35 & 550 & 10 & $7.34 \pm 1.08$ & $153 \pm 13$ & $7.37 \pm .88$ & $158 \pm 4$ & $40.4 \pm 3$ \\
\hline 35 & 550 & 162 & $7.92 \pm 0.46$ & $140 \pm 6$ & $7.41 \pm 0.81$ & $131 \pm 11$ & $36.25 \pm 9$ \\
\hline 45 & 500 & 162 & $7.25 \pm 0.36$ & $145 \pm 6$ & $7.13 \pm 0.27$ & $140 \pm 5$ & $55.3 \pm 3$ \\
\hline 45 & 550 & 10 & $6.78 \pm 0.26$ & $139 \pm 6$ & $6.72 \pm 0.14$ & $136 \pm 4$ & $51.6 \pm 3.2$ \\
\hline 45 & 550 & 162 & $6.63 \pm 0.44$ & $143 \pm 9$ & $6.18 \pm 0.52$ & $131 \pm 7$ & $45.5 \pm 7$ \\
\hline 35 & \multicolumn{2}{|c|}{ as-deposited } & $4.1 \pm 0.37$ & $112 \pm 4$ & $4.2 \pm 0.4$ & $113 \pm 5$ & $60 \pm 10$ \\
\hline Pure Ti & \multicolumn{2}{|c|}{$\mathrm{n} / \mathrm{a}$} & $1.43 \pm 0.28$ & $119 \pm 5$ & $1.23 \pm 0.22$ & $113 \pm 10$ & $60 \pm 5$ \\
\hline Pure Ta & \multicolumn{2}{|l|}{$\mathrm{n} / \mathrm{a}$} & $1.96 \pm 0.25$ & $180 \pm 15$ & $1.5 \pm 0.2$ & $182 \pm 12$ & $59 \pm 6$ \\
\hline
\end{tabular}

All measured quantities are reported as average \pm standard deviation.

linear decrease with increasing depth due to the rising influence of the $\mathrm{Zr}$ substrate, which is softer than the nanocomposite film. At these depths, the dimensions of the projected area probed by the Berkovich tip are an order of magnitude larger than the average size of the microstructural features in the nanocomposite film. A previous study by McCue et al. on metal composites made by liquid metal dealloying (LMD) showed that indents whose depths are of the order the feature size are large enough to measure a representative volume of the material. ${ }^{[34]}$ With one exception, the feature size in our samples is well below $100 \mathrm{~nm}$ (see Table II). Therefore, we expect that indents made to a depth of 50 to $150 \mathrm{~nm}$ sample a representative volume of the microstructure.

We determined film hardness and modulus from monotonic indents made to depths of 50 and $100 \mathrm{~nm}$, corresponding to 10 and 20 pct the film thickness, respectively. Table III lists these quantities for all samples after averaging over all sixteen independent indents made in each sample. Figure 7 compares the hardness and modulus values at an indentation depth of $50 \mathrm{~nm}$ across the samples in our study. The elastic moduli of all composites fall within a range from 121 to $153 \mathrm{GPa}$. This range may be rationalized from the rule of mixtures: using the phase compositions and area fractions listed in Table II and the elastic modulus values of pure $\mathrm{Ta}$ and $\mathrm{Ti}$ in Table III, we expect composite values ranging from 108 to $151 \mathrm{GPa}$. There appears to be no dependence of elastic moduli on feature size or microstructure morphology type.

Hardness in our Ta/Ti composites varies from 6.4 to 7.9 $\mathrm{GPa}$, with an average of $7.1 \mathrm{GPa}$ across all the samples. These values are substantially in excess of the rule-of-mixtures hardness calculated from the reference sample data in Table III, which ranges from 2.2 to 3.3 $\mathrm{GPa}$ for all phase compositions and area fractions reported in Table III. This enhancement in hardness is consistent with previous studies on other types of metal nanocomposites - such as multilayers ${ }^{[10,35]}$ - and is the outcome of confinement of dislocations within nanoscale grains with high interface area per unit volume. ${ }^{[36,37]}$ Remarkably, as in the case of elastic modulus, we do not observe any correlation between hardness and feature size or microstructure morphology type in our samples. However, this lack of correlation can be rationalized by the small spread in feature sizes across all 12 samples.

Finally, Figure 8 shows non-dimensional modulus-to-hardness ratios, $E / H$, for all of our samples. This ratio is a useful metric for evaluating whether indentation load-displacement response is dominated by elastic or the plastic deformation. ${ }^{[38]}$ Materials with elasticity-dominated indentation response, such as silicate glasses, have $E / H \approx 12.0$. By contrast, materials such as aluminum exhibit plasticity-dominated indentation response with $E / H \approx 118$. Due to their high hardness, all of our Ta/Ti composites consistently exhibit ratios of $E / H \approx 19$, regardless of feature size or microstructure morphology. Thus, their indentation response may be considered to be dominated by elastic deformation.

\section{B. Pileup Behavior}

Representative surface scans of cube-corner indents on two different $\mathrm{Ta} / \mathrm{Ti}$ composites are shown in Figures 9(a) and (b). In the case of the sample with parent alloy composition $\mathrm{Ta}_{35} \mathrm{Ti}_{65}$ shown in Figure 9(a), the scan reveals a substantial pileup. Meanwhile, almost no sign of pileup may be seen in the case of the sample with $\mathrm{Ta}_{15} \mathrm{Ti}_{85}$ parent alloy composition in Figure 9(b). To better quantify this difference, we extracted surface heights along lines passing perpendicular to one of the indent edges and through the opposing indent corner, as shown in Figures 9(a) and (b). Figure 9(c) plots surface heights as a function of position along these lines, confirming substantial pileup along the indent edge in the sample in Figure 9(a) and no apparent pileup in the Figure 9(b) sample. For each indent, we extracted three 


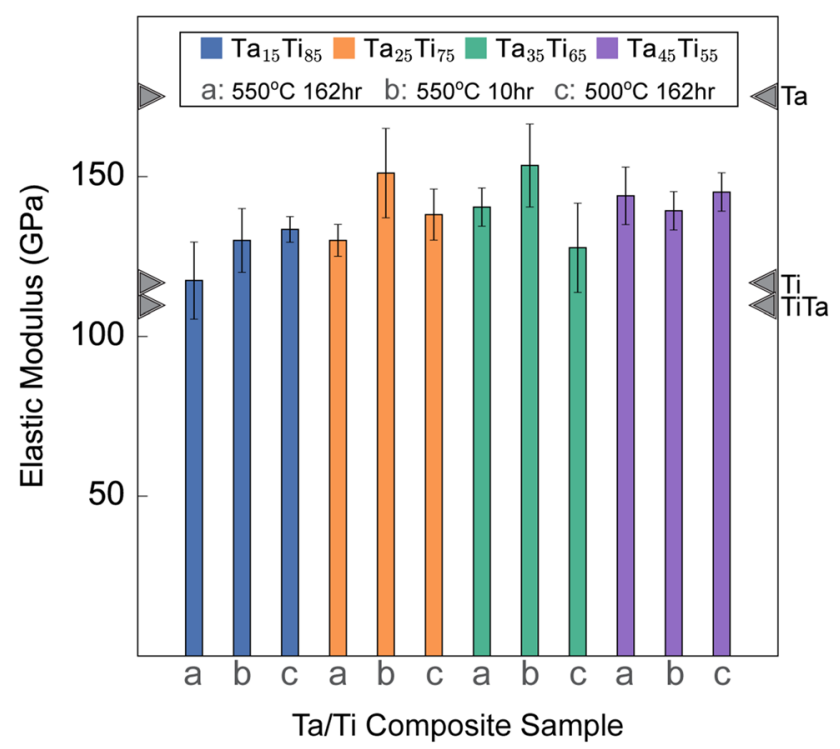

(b)

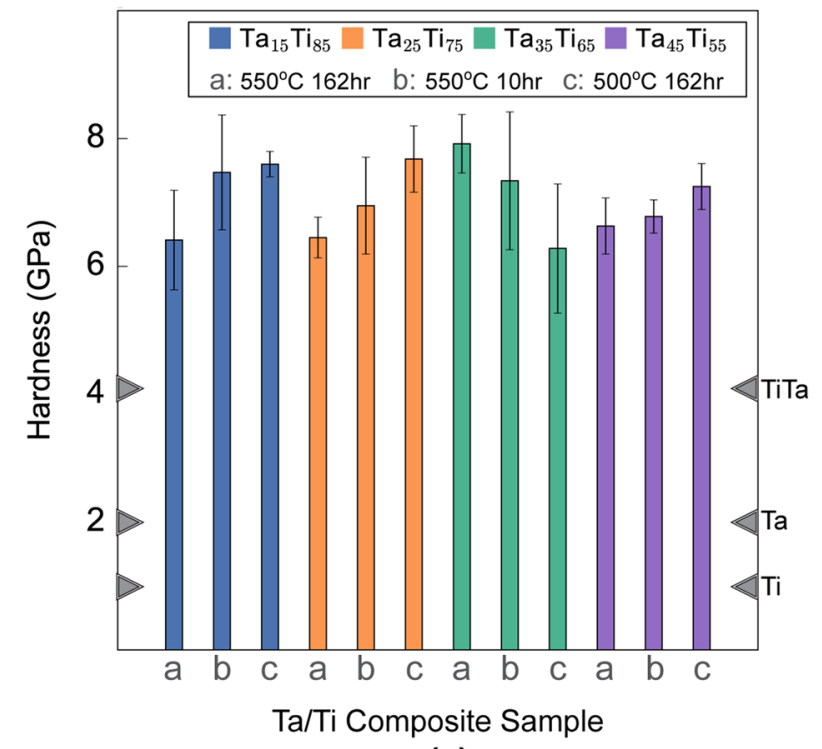

(a)

Fig. 7-Indentation (a) modulus and (b) hardness determined from monotonic indents to a depth of $50 \mathrm{~nm}$. Measurements of the pure phases and a representative as-deposited film (gray arrows) are included on the $y$-axes as a reference. Although the composite samples have widely differing microstructure morphologies, their hardness and modulus values are comparable.

surface height line profiles - one passing through each indent corner - and found the maximum pileup height in each profile.

We carried out such surface analysis on each of the cube-corner indents. The resulting pileup data, presented in Table III, include the average and standard deviation of pileup height for each sample. Seeking correlations between pileup height and the data in Tables II and III, we found that pileup height is nearly linearly proportional to the $\mathrm{Ta}$ area fraction in the composite, as shown in Figure 10. Pileup height is lowest for samples with the smallest Ta-rich phase fractions and greatest for samples with highest Ta-rich

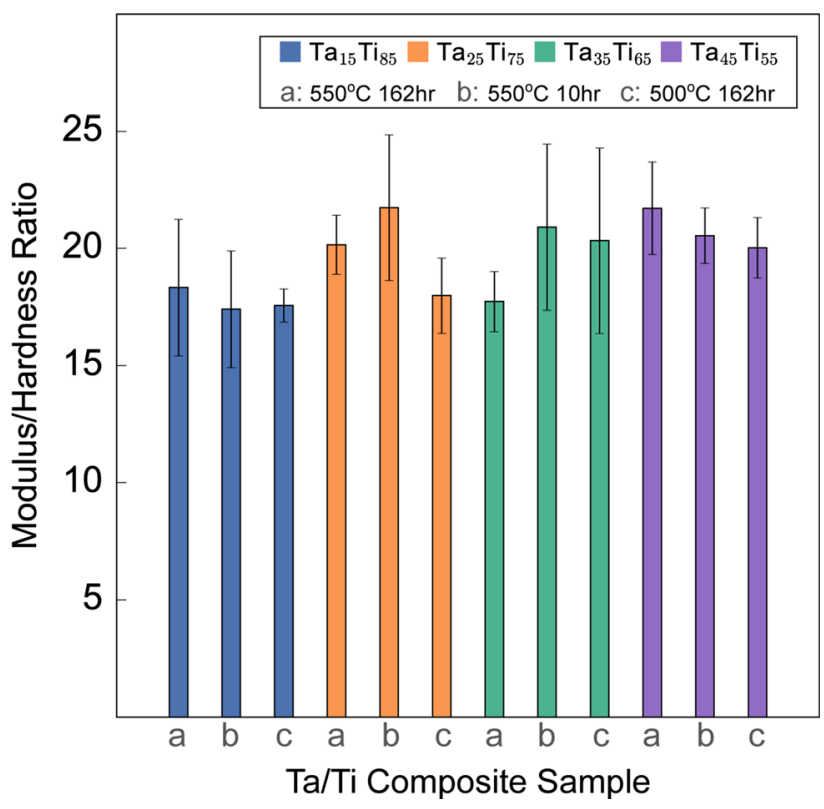

Fig. 8-Indentation modulus-to-hardness ratios, $E / H$, for the Nanocomposites calculated based on the data in Fig. 9.

area fraction. We found no other correlations between pileup height and the morphological or mechanical data in Tables II and III.

To better understand the differences in pileup behavior in samples with disparate Ta-rich phase fractions, we performed FIB cross sections under two cube-corner indents corresponding to extreme cases of pileup height: one with the greatest pileup we observed and parent alloy composition $\mathrm{Ta}_{45} \mathrm{Ti}_{55}$, the other with least pileup and parent alloy composition $\mathrm{Ta}_{15} \mathrm{Ti}_{85}$. For comparison, we also created FIB cross sections through the un-indented parts of the same composite samples. The resulting images are shown in Figure 11. In addition to the secondary electron micrographs, we also present binarized images of the microstructure obtained using AQUAMI. ${ }^{[17]}$ The latter highlight the distribution of the individual phases within the samples.

The sample with parent alloy composition $\mathrm{Ta}_{45} \mathrm{Ti}_{55}$ consists of a highly interconnected Ta matrix containing non-percolating Ti particles, as shown in Figures 11(a) and (b). Conversely, the sample with parent alloy composition $\mathrm{Ta}_{15} \mathrm{Ti}_{85}$ contains a highly connected $\mathrm{Ti}$ matrix with non-percolating $\mathrm{Ta}$ particles, as in Figures 11(e) and (f). We cannot make one-to-one comparisons between individual microstructural features in the indented and un-indented cross sections shown in Figure 11 as they were taken from different regions of the composite samples. Qualitative differences in the effect of indentation on microstructure may nevertheless be surmised by contrasting these samples.

In particular, most of the Ti-rich particles in the un-indented region shown in Figure 11(a) and (b) have high aspect ratio with their long axis oriented perpendicular to the sample surface. Examining Figures 11(c) and (d), we see that several particles in the region under the indent are nearly equiaxed. This observation 


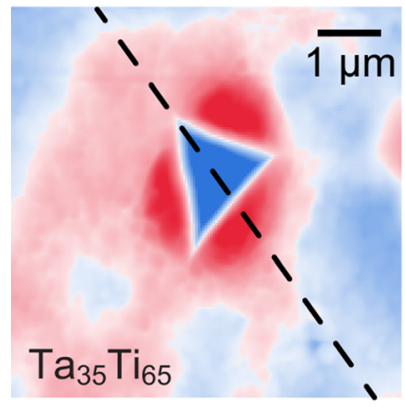

(a)

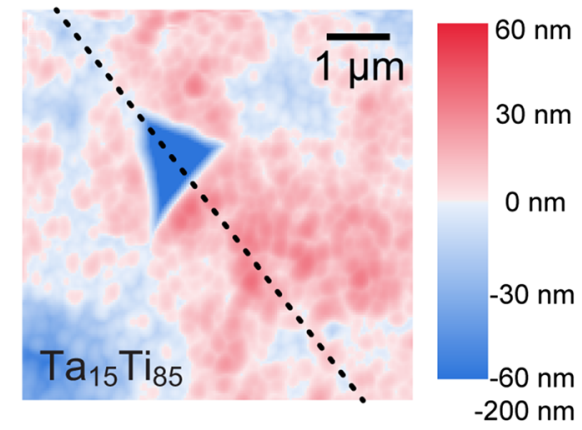

(b)

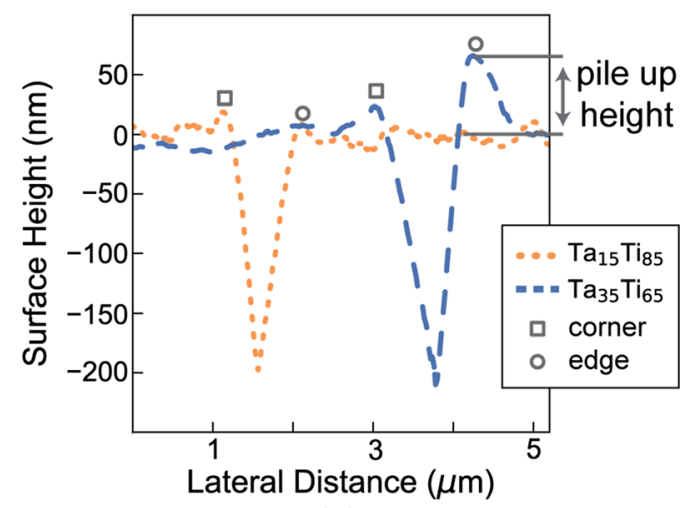

(c)

Fig. 9-Representative surface scans showing pileups around cube-corner indents for composites with parent alloy compositions of $(a) \mathrm{Ta}_{35} \mathrm{Ti}_{65}$ and $(b) \mathrm{Ta}_{15} \mathrm{Ti}_{85}$. Line profiles of surface height were extracted along the dashed black lines and plotted in $(c)$.

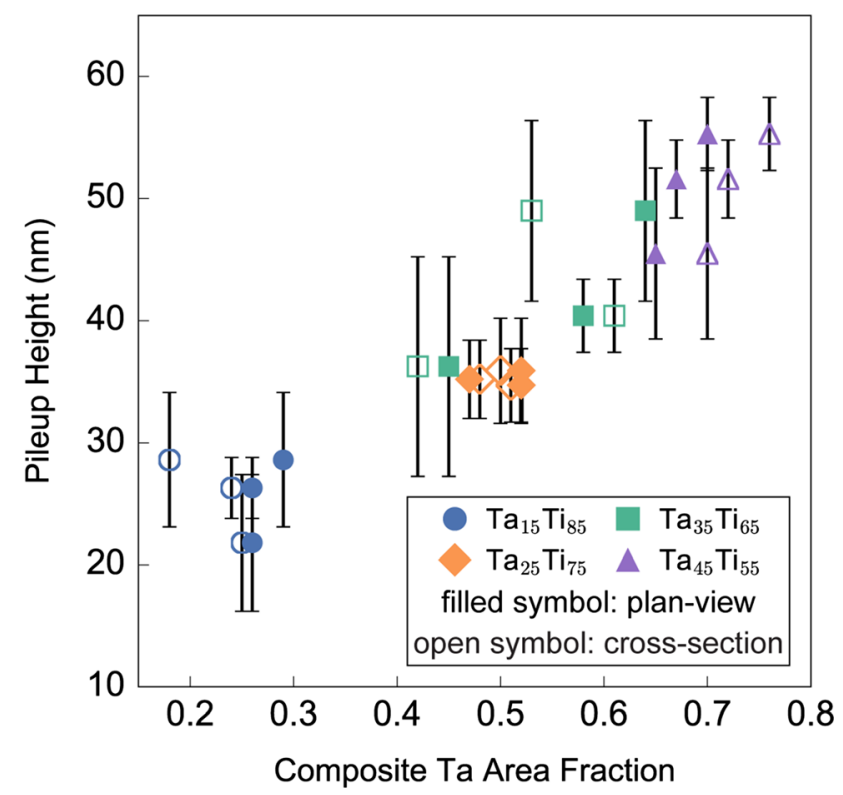

Fig. 10 - Correlation between indentation pileup height and the area fraction of the Ta-rich phase. Filled symbols indicate data from plan-view images and open symbols from cross sections.

suggests that Ti-rich inclusions were deformed into new shapes by the indentation. Similar to these Ti-rich particles, the Ta-rich particles in Figures 11(e) and (f) also appear to have high aspect ratios. However, the region under the indent in Figures $11(\mathrm{~g})$ and $(\mathrm{h})$ does not appear to contain equiaxed particles, suggesting that the Ta-rich particles did not co-deform with the matrix during indentation. In the discussion section, we argue that these different deformation behaviors are related to the different pileup heights observed in our samples.

\section{DISCUSSION}

We have synthesized $\mathrm{Ta} / \mathrm{Ti}$ nanocomposite thin films with a range of different microstructure morphologies, feature sizes, and phase fractions and investigated their indentation response. We did not find any systematic influence of microstructure morphology on indentation modulus or hardness. However, we observed a direct relationship between the phase fractions in the composite and indentation pileup behavior. Below, we propose potential explanations for this phenomenon in terms of the constitutive properties of the nanocomposites as well as underlying fundamental mechanisms of mechanical deformation.

We expect that the elastic properties of our nanocomposites are determined to two primary factors: the composition of the constituent phases and the morphology of the microstructure. Local compositions change markedly as the parent $\mathrm{Ta}_{x} \mathrm{Ti}_{1-x}$ alloy phase separates. During this process, both phases remain in the form of solid solutions whose elastic properties are expected to take on intermediate values between those of the constituent elements. Therefore, consistent with our findings, variations in elastic moduli during Ti re-distribution are expected to be bounded by the moduli of $\mathrm{Ti}$ and $\mathrm{Ta}$ (and, to a lesser extent, of $\mathrm{Zr}$ ). Had the heat treatment reaction resulted in the formation of intermetallic compounds in either the parent alloy or the solvent, then the expected bounds on the moduli of the composite may have to be expanded to include the moduli of these compounds, as well. However, consistent with previous studies on the Ta-Ti-Zr system, ${ }^{[39]}$ no intermetallics were seen in this work.

The morphology of constituent phases is known to affect the volume-averaged elastic properties of composite materials. Predicting the latter from the former is one of the aims of homogenization theory. In all cases, however, bounds on the homogenized linear elastic moduli of composites are the moduli of the constituent phases themselves. ${ }^{[40]}$ Therefore, regardless of microstructure morphology, the elastic moduli of all our nanocomposites are expected to remain bounded by those of Ti and Ta.

An exception to this rule may arise if the characteristic dimensions of microstructural features drop to the single nanometer level. Studies on two-component multilayer composites with layer thicknesses on this order indicate that some elastic moduli may exhibit a reduction up to several tens of percent below 
$\mathrm{Ta}_{45} \mathrm{Ti}_{55}$

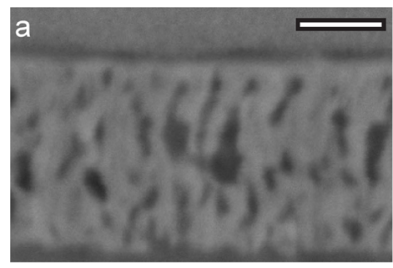

unindented

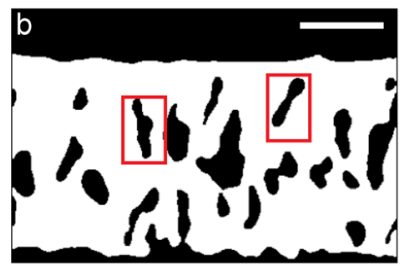

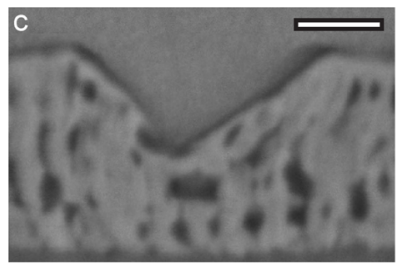

indented

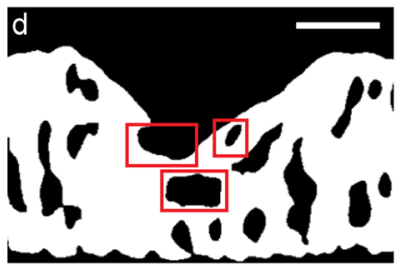

$\mathrm{Ta}_{15} \mathrm{Ti}_{85}$

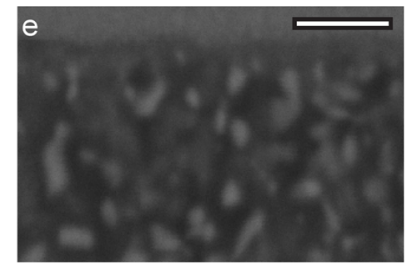

unindented

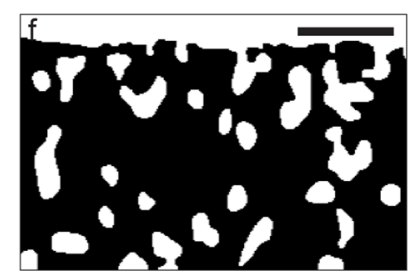

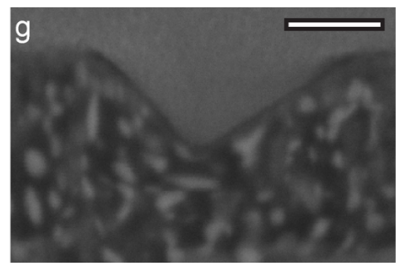

indented

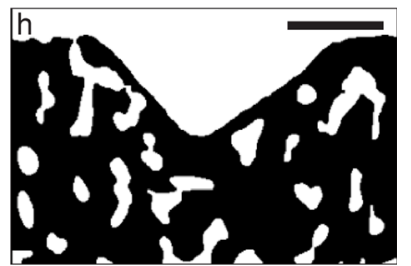

Fig. 11-Comparison of deformation behavior between two composite morphologies. $(a)$ through $(d) \mathrm{Ta}_{35} \mathrm{Ti}_{65}$ and $(e)$ through $(h) \mathrm{Ta}_{15} \mathrm{Ti}_{85}$. Black (Ti phase) and white (Ta phase) images converted from scanning electron micrographs (a, c) and (e, g). Gray features in (e, g) are not a third phase, but rather contrast from local variations in the Ti:Zr ratio in the solvent. Red boxes in (b, d) suggest changes in shape of Ti particles under the cube-corner indent. Representative images of Ti matrix/Ta particle composite morphology before and after deformation (f, h) suggest little change in the shape of Ta particles under the cube-corner indent. Scale bars in (a, c, e, g) represent 200 nm.

homogenization theory predictions. ${ }^{[41-43]}$ This effect is due to the fact that, for such low constituent dimensions, a significant fraction of the atoms in the material are located at or near the interfaces between adjacent constituents. Thus, the reduced moduli of such composites may be ascribed to interfaces behaving as a third, low stiffness composite constituent. ${ }^{[4]}$ For composites such as ours, where characteristic feature sizes are on the order of several tens of nanometers, this effect is negligible.

Unlike modulus, the indentation hardness of our nanocomposites exhibits a clear departure from the rule of mixtures: as shown in Figure 7, the composites show hardness enhancements of 3 to $4.5 \mathrm{GPa}$ beyond those of pure $\mathrm{Ti}$, pure $\mathrm{Ta}$, and as-deposited $\mathrm{Ta}_{35} \mathrm{Ti}_{65}$ alloy. This phenomenon is consistent with a broad range of previous studies on the mechanical properties of nano-metallic materials (NMMs), including metal multilayer composites ${ }^{[35]}$ and polycrystals with sub-100 nm grain sizes. ${ }^{[6,37]}$ Although there is ongoing debate about the detailed mechanisms that govern the strength of such materials, ${ }^{[45]}$ the confinement of dislocations to small volumes by interfaces (grain and phase boundaries) is a key ingredient in all proposed explanations. Interfaces are obstacles to dislocation motion, causing dislocations to accumulate and generate back stresses, elevating the applied loads required for continued deformation. ${ }^{[1,2]}$ They may also behave as dislocation sinks, giving rise to dislocation starvation within individual crystalline domains. ${ }^{[46]}$ We invoke the same general reasoning to explain the elevated hardness of our composites, as both the constituent phases as well as the grains from which they are composed have sub-100 nm dimensions.

The most unexpected mechanical behavior exhibited by our nanocomposites is the clear, monotonic correlation between Ta-rich phase fraction and indentation pileup height shown in Figure 10. We interpret this result following the analysis of Bolshakov and Pharr, ${ }^{[38]}$ who used finite element calculations to investigate the effect of modulus, hardness, and strain hardening rate on indentation pileup height. They found that, for fixed indenter load and $E / H$ ratio, pileup height is determined by the strain hardening rate. As shown in Figure 8, the $E / H$ ratios of our samples are nearly equal, to within experimental uncertainty. Thus, the variations in pileup height we observed indicate differing strain hardening rates in the nanocomposites, with large pileup associated with low work hardening and small pileup with high work hardening. ${ }^{[47]}$ Figure 10 therefore shows that the lower the Ta-rich phase fraction in nanocomposites, the higher the strain hardening rate. Pure Ti, pure Ta, and the as-deposited TaTi alloy all exhibit relatively large pileups, suggesting low hardening. However, a direct comparison between them and the nanocomposites cannot be made because the $E / H$ ratios of the former are substantially larger than those of the latter.

Indentation pileup height has been previously used to compare hardening rates in NMMs, notably in investigations on metal multilayer nanocomposites. ${ }^{[20]}$ Further confirmation of hardening trends may be obtained by using pyramidal indenters with different tip angles, enabling measurements of hardness as a function of the maximum plastic strain under the indenter. ${ }^{[48,49]}$ Conclusive demonstrations of hardening rates, however, require tests conducted using uniform stress states, such as uniaxial tensile or compression tests. For materials synthesized in thin-film form, compression of micropillars machined using FIB milling is the most practical approach to conducting uniaxial deformation experiments. ${ }^{[50]}$ These tests, however, suffer from challenges of their own. For example, small volumes of material are prone to strain bursts, making it difficult to extract quantitative work hardening behavior. ${ }^{[51]}$ 
Many NMMs exhibit low levels of strain hardening, as evidenced by their nearly flat true stress-strain curves. ${ }^{[4]}$ Lack of hardening is related to the sub- 100 $\mathrm{nm}$ dimensions of microstructural features in these materials. Polycrystalline metals with micron-scale grains generally harden readily due to dislocation-dislocation interactions. ${ }^{[52]}$ This hardening mechanism is not significant in NMMs, where nanometer-scale microstructure dimensions prevent the buildup of high dislocation densities, thereby keeping the frequency of dislocation-dislocation interactions low. ${ }^{[53]}$ Previous efforts to impart hardening to NMMs have focused on non-dislocation-based mechanisms, such as introducing nano-scale twins, ${ }^{[3]}$ second phases, ${ }^{[54]}$ precipitates, ${ }^{[55]}$ and non-equilibrium grain boundary structures. ${ }^{[2]}$

To elucidate the mechanisms responsible for hardening in our nanocomposites, we focus on the monotonic variation of pileup height with Ta-rich phase fraction in Figure 10. These data suggest that hardening in our $\mathrm{Ta} /$ Ti composites is not determined by the connectivity of the phases alone. Phase connectivity in general, isotropic, two-phase composites varies symmetrically with phase fraction, ${ }^{[40]}$ consistent with Figure 3. At low Ta-rich phase fraction, the microstructure contains isolated Ta-rich particles or rods embedded in a percolating $\mathrm{Ti}$ matrix. As the Ta-rich phase fraction increases, Ta-rich particles interconnect and eventually percolate. When the Ta- and Ti-rich phase fractions are comparable, both phases percolate simultaneously, forming a "bicontinuous" microstructure morphology. ${ }^{[25,26]}$ Finally, when the Ta-rich phase fraction exceeds the Ti-rich phase fraction by a sufficiently large margin, the latter ceases to percolate, forming isolated Ti-rich particles embedded in a Ta-rich matrix. Thus, had hardening been governed primarily by the connectivity of the phases in our nanocomposites, we would expect pileup height to vary approximately symmetrically about a composite phase fraction of 50 pct. The monotonic variation actually observed therefore rules out connectivity as the primary factor governing hardening in these materials.

One potential explanation for monotonic variation of hardening with phase fraction is that the Ta-rich phase simply has a higher hardening rate than the Ti-rich phase and that the hardening of the composite follows the rule of mixtures. Two factors militate against such an explanation. First, the data reported in Table III show that pure Ti and pure Ta have nearly equal pileup heights, suggesting that their hardening rates are also comparable. This conclusion cannot be made definitively, as $E / H$ ratios of these materials differ by about a factor of two. Moreover, indentations on pure elements are not fully representative of the composite phases, since the latter are solid solutions. Nevertheless, low contrast in pileup puts into doubt a large difference in hardening rate.

More importantly, at $1.5 \mathrm{GPa}$, the hardness of pure $\mathrm{Ta}$ and pure $\mathrm{Ti}$ is substantially lower than that of the composite, which is never below $6 \mathrm{GPa}$. As already discussed above, this enhancement in hardness is not due to the properties of the individual phases, but rather the confinement of dislocation motion by the nano-scale dimensions of the microstructural elements that make up the composite itself. Thus, for hardening in either of the constituent phases to influence the aggregate response of the composite, it would have to independently elevate the hardness of one or both of the components above $6 \mathrm{GPa}$. Given that the maximum plastic strain under a Berkovich indenter is on the order of 8 pct ${ }^{[19,21]}$ hardening rates around $50 \mathrm{GPa}$ would be required, i.e., an order of magnitude larger than rates found in conventional engineering alloys, which are typically on the order of $1 \mathrm{GPa} .{ }^{[56]}$ Therefore, we view it as highly unlikely that the monotonic variation of pileup with Ta-rich phase fraction in Figure 10 is due to a rule-of-mixtures dependence on hardening rates in the individual composite constituents.

We hypothesize a mechanism of strain hardening in our nanocomposites motivated by the FIB cross sections shown in Figure 12. These images suggest that both constituent phases undergo plastic deformation under the indenter when the fraction of the Ta-rich phase is high and the microstructure may be viewed as nanoscale Ti-rich inclusions in a Ta-rich matrix. This case leads to the highest pileup and therefore the lowest expected hardening rate. By contrast, in composites consisting of Ta-rich inclusions embedded in a Ti-rich matrix, the inclusions appear not to be codeforming with the matrix. This case exhibits the lowest pileup and consequently the highest expected hardening rate.

Thus, it appears that highly deformable particles in a matrix lead to less hardening, while comparatively rigid particles lead to more hardening. Figure 12 illustrates our hypothesis for how this distinction arises and connects it to indentation pileup height. Figure 12(a) illustrates dislocations moving through the Ta-rich matrix during deformation. Owing to co-deformation of both phases, dislocations are not stored, which leads to perfectly plastic behavior. If we extend this illustration to indentation, Figure 12(b), plasticity-initiated along planes of highest resolved shear stress under the tip - is not impeded. Material therefore flows continuously from beneath the indenter to the free surface around the indent, giving rise to a large pileup. However, for the case of the Ti-rich matrix, Figure 12(c), the non-deforming Ta particles cause Ti dislocations to see significant back stresses from previous slip events, leading to kinematic strain hardening behavior. If we extend this illustration to indentation, Figure 12(d), material flow to the free surface initiates at a location with highest resolved shear stress, but soon shuts down due to the back stresses of accumulated dislocations. Flow then re-initiates at a more distant location. As this process repeats, material flow to the free surface is spread out around the indent, giving rise to lower pileup.

It remains to be explained why Ta-rich particles do not co-deform with the Ti-rich matrix while Ti-rich particles in a Ta-rich matrix do. We propose that, ultimately, the distinction arises because $\mathrm{Ta} / \mathrm{Ti}$ interfaces interact differently with impinging dislocations depending on whether the dislocations originate from the Ta- or the Ti-rich phase. In particular, we conjecture that $\mathrm{Ta} / \mathrm{Ti}$ interfaces are strong sinks for dislocations 


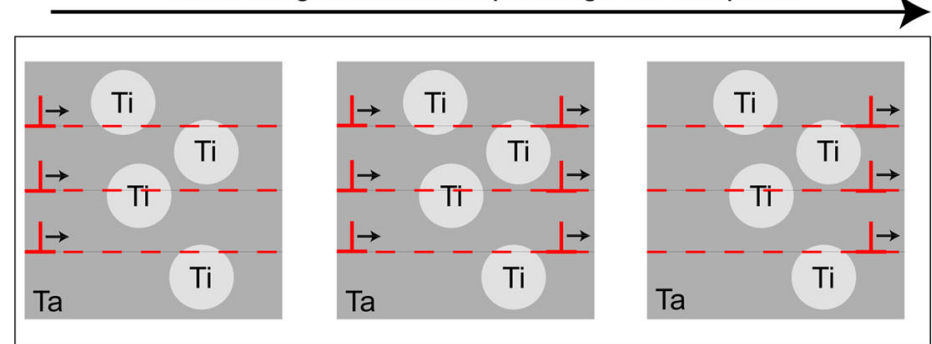

(a)

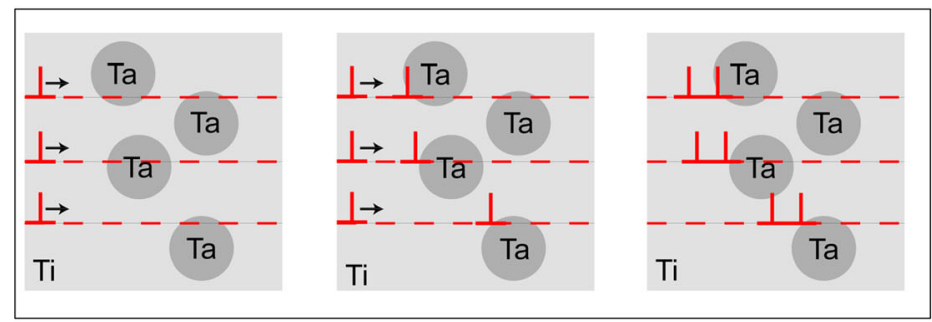

(c)

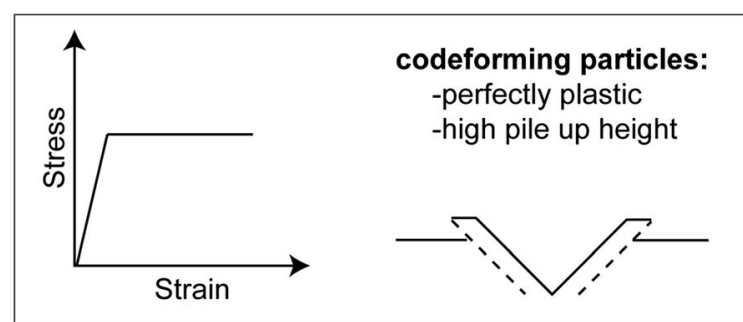

(b)

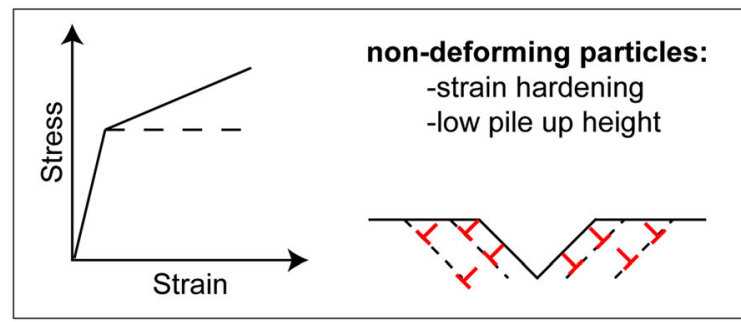

(d)

Fig. 12-Hypothesized deformation mechanisms for the Ta-rich and Ti-rich matrix composites. (a) Ta dislocations moving through the Ta-rich matrix. Consistent with co-deformation of the Ta matrix and Ti particles, Ta dislocations move through the material unimpeded by previous slip events. (b) Thus, material easily flows from under the indent to the free surface around the impression, leading to large pileups. (c) Ti dislocations moving through the Ti-rich matrix. Since the Ta particles are non-codeforming, Ti dislocations see significant back stresses from previous slip events, which leads to kinematic strain hardening. (d) Thus, material flow to the free surface repeatedly initiates and shuts down along bands at ever greater distances from the indent, leading to low pileups.

originating from the $\mathrm{Ti}$ grain, absorbing them easily, while dislocations originating from the Ta grain are not easily absorbed and instead pile up at the interface. We also assume that all grain boundaries are strong sinks for dislocations.

Under the foregoing assumptions, each $\mathrm{Ti}$ grain is fully surrounded by interfaces that are strong dislocation sinks. Thus, when these grains have nano-scale dimensions, dislocations are easily and continuously removed from them, leading to dislocation starvation. The flow stress in the Ti grains is therefore always set by the stress needed to generate new dislocations from persistent sources, ${ }^{[46]}$ regardless whether the Ti-rich particles are isolated or interconnected. By contrast, dislocations within Ta grains only have access to strong dislocation sinks - specifically, grain boundaries - when the Ta grains are interconnected. If so, then dislocations may be removed from the Ta grains, once again giving rise to dislocation starvation. However, dislocations in isolated Ta-rich particles embedded in a Ti-rich matrix have no access to strong sinks. Consequently, these dislocations pile up against $\mathrm{Ta} / \mathrm{Ti}$ interfaces, generating back stresses that elevate the external load needed to operate local dislocation sources and eventually shifting plasticity to more distant locations, as illustrated in Figure 12.

The hypothesis presented above is broadly aligned with the notion, reviewed in detail in Reference [7], that interface/dislocation interactions - including dislocation nucleation, absorption, and transmission-vary with interface structure and composition. The majority of previous studies underpinning this view were carried out on interfaces involving face-centered cubic (FCC) or body-centered cubic (BCC) metals, ${ }^{[10,35,57]}$ with relatively few investigations focusing on interfaces involving hexagonal close-packed (HCP) metals. ${ }^{[58-60]}$ In particular, we are not aware of any previous investigations on dislocation interactions with interfaces between BCC Ta and HCP Ti.

There are only a handful of mechanical behavior studies on morphologically complex, metal nanocomposites to which we can compare our results. Cui et al. performed micropillar compression tests ${ }^{[50]}$ on $\mathrm{Cu} / \mathrm{Mo}$ nanocomposites formed by phase separation during high-temperature co-sputtering. ${ }^{[61]}$ They reported suppression of shear banding in these materials when the morphology changed from alternating $\mathrm{Cu} / \mathrm{Mo}$ layers to a bicontinuous network, suggesting that work hardening may be higher in the latter. By contrast, the bicontinuous morphology in our study did not possess the best combination of high hardness and low pileup. Vüllers and Spolenak ${ }^{[62]}$ examined the hardness of $\mathrm{W} / \mathrm{Cu}$ composites formed by co-sputtering and subsequent annealing. Examining a wide range of compositions and annealing conditions, they found that hardness in these composites follows the rule of mixtures, once again in contrast with the findings reported here for nanocomposites. Finally, McCue et al. examined the hardness and flow strength of $\mathrm{Ta} / \mathrm{Cu}$ bicontinuous composites made by LMD of $\mathrm{Ta}_{35} \mathrm{Ti}_{65}$ alloys in molten $\mathrm{Cu}$ and molten $\mathrm{CuAg}$. By varying the ligament diameter from $\sim 70 \mathrm{~nm}$ to $\sim 10 \mu \mathrm{m}$, they found that the yield strength has a significant size dependence and reaches levels exceeding the rule of mixtures by a factor of two for the 
nanostructured composite. ${ }^{[63]}$ However, they did not investigate the effect of composite morphology on mechanical response.

The contrast between our work and the aforementioned previous investigations shows that the optimal microstructure morphology for our $\mathrm{Ta} / \mathrm{Ti}$ nanocomposites cannot be assumed optimal for other materials, such as $\mathrm{Cu} / \mathrm{Mo}$ or $\mathrm{W} / \mathrm{Cu}$ nanocomposites. This view is consistent with the bimetal interface/dislocation interactions being the most important factor governing mechanical properties. It is this interaction that dictates the optimum composite morphology, especially insofar as the latter affects the type and connectivity of interfaces present in nanocomposites. Furthermore, since interface/ dislocation interactions depend on interface composition and structure ${ }^{[7]}$ composites with different interface types may possess different optimal microstructure morphologies. Thus, for $\mathrm{Ta} / \mathrm{Ti}$ composites, flow uniformity is highest when the Ta phase is non-percolating, but other materials, such as $\mathrm{W} / \mathrm{Cu}$ or $\mathrm{Cu} / \mathrm{Mo}$ composites, may exhibit optimal flow uniformity when both phases are interpenetrating bicontinuous networks.

The lack of uniform deformability in NMMs has been an impediment to their widespread technological use. Uniform deformation-i.e., plasticity free from flow localization - is a pre-requisite for deformation-based processing methods, such as shaping and forming, as well as for applications that require significant deformation prior to failure, as in energy absorption. Plastic instabilities arise from the interplay of numerous factors, including material architecture (morphology, microstructural length scale), defects and flaws (cracks, inclusions), and loading conditions (tension vs. compression, static vs. dynamic).$^{[64-67]}$ Low strain hardening and low strain rate hardening, however, are prime materials properties contributing to localization. ${ }^{[1]}$ Increasing hardening by one or both of these mechanisms promises to reduce flow localization in NMMs, hastening the transition of these materials to technological use.

Our work expands the scope of investigations on plastic flow uniformity in NMMs beyond previous studies, many of which focused on the effect of nano-scale inhomogeneities. ${ }^{[3,55,68]}$ In single-phase materials, such inhomogeneities might be grains of widely differing dimensions, as in materials with bimodal ${ }^{[69]}$ or hierarchical grain size distributions, ${ }^{[70,71]}$ or high densities of nanotwins. ${ }^{[72]}$ Investigations on multiphase materials have relied on the introduction of nanoprecipitates or dendrites. ${ }^{[73,74]}$ Our work shows that tailoring the microstructure morphology of NMMs is another promising route to achieving high strength while simultaneously improving strain hardening and therefore flow uniformity.

\section{ACKNOWLEDGMENTS}

This work was supported by the NSF DMREF program under Grant \#1623051. We thank J. K. Baldwin for thin-film deposition and both G. Pharr and B. Crawford for helpful discussions regarding indentation pileup and the impact of an underlying substrate. This work was performed, in part, at the Center for Integrated Nanotechnologies, an Office of Science User Facility operated for the U.S. Department of Energy (DOE) Office of Science. Use of the TAMU Materials Characterization Facility is acknowledged.

\section{REFERENCES}

1. E. Ma: Scr. Mater., 2003, vol. 49, pp. 663-68.

2. E. Ma: $J O M, 2006$, vol. 58 , pp. 49-53.

3. E. Ma and T. Zhu: Mater. Today, 2017, vol. 20, pp. 323-31.

4. C.C. Koch, D.G. Morris, K. Lu, and A. Inoue: MRS Bull., 1999, vol. 24 , pp. $54-58$.

5. C. Koch: Scr. Mater., 2003, vol. 49, pp. 657-62.

6. Z.C. Cordero, B.E. Knight, and C.A. Schuh: Int. Mater. Rev., 2016, vol. 61, pp. 495-512.

7. I.J. Beyerlein, M.J. Demkowicz, A. Misra, and B.P. Uberuaga: Prog. Mater. Sci., 2015, vol. 74, pp. 125-210.

8. Y.-C. Wang, A. Misra, and R.G. Hoagland: Scr. Mater., 2006, vol. 54, pp. 1593-98.

9. T.J. Rupert and C.A. Schuh: Acta Mater., 2010, vol. 58, pp. $4137-48$

10. A. Misra and T. Ludovic: MRS Bull., 2010, vol. 35, pp. 965-77.

11. E.M. Bringa, J.D. Monk, A. Caro, A. Misra, L. Zepeda-Ruiz, M. Duchaineau, F. Abraham, M. Nastasi, S.T. Picraux, Y.Q. Wang, and D. Farkas: Nano Lett., 2012, vol. 12, pp. 3351-55.

12. A. Misra, M.J. Demkowicz, X. Zhang, and R.G. Hoagland: JOM, 2007, vol. 59, pp. 62-65.

13. H.-J. Jin, J. Weissmüller, and D. Farkas: MRS Bull., 2018, vol. 43, pp. 35-42.

14. H.-J. Jin and J. Weissmüller: Adv. Eng. Mater., 2010, vol. 12, pp. 714-23.

15. M.J. Demkowicz: MRS Bull., 2019, vol. 44, pp. 25-30.

16. I. McCue and M.J. Demkowicz: JOM, 2017, vol. 69, pp. 2199-2205.

17. J. Stuckner, K. Frei, I. McCue, M.J. Demkowicz, and M. Murayama: Comput. Mater. Sci., 2017, vol. 139, pp. 320-29.

18. L.A. Giannuzzi, J.L. Drown, S.R. Brown, R.B. Irwin, and F.A. Stevie: Microsc. Res. Tech., 1998, vol. 41, pp. 285-90.

19. J.L. Bucaille, S. Stauss, E. Felder, and J. Michler: Acta Mater., 2003, vol. 51, pp. $1663-78$

20. A. Bellou, C.T. Overman, H.M. Zbib, D.F. Bahr, and A. Misra: Scr. Mater., 2011, vol. 64, pp. 641-44.

21. D.S. Dugdale: J. Mech. Phys. Solids, 1954, vol. 2, pp. 265-77.

22. Gnu Image and L. gimp. or. Manipulation Program.

23. A.V. Dobromyslov, G.V. Dolgikh, Y. Dutkevich, and T.L. Trenogina: Phys. Met. Metallogr., 2009, vol. 107, pp. 502-10.

24. K.A. Bywater and J.W. Christian: Philos. Mag., 1972, vol. 25, pp. 1249-73.

25. S.G. Corcoran, D. Wiesler, J. Barker, and K. Sieradzki: $M R S$ Proc., 1994, vol. 376, p. 77.

26. Y. Kwon, K. Thornton, and P.W. Voorhees: Phys. Rev. E, 2007, vol. 75 , p. 021120

27. Q. Chen and K. Sieradzki: Nat. Mater., 2013, vol. 12, pp. 1102-06.

28. J. Erlebacher: Phys. Rev. Lett., 2011, vol. 106, p. 225504.

29. I. McCue, J. Stuckner, M. Murayama, and M.J. Demkowicz: Sci. Rep., 2018, vol. 8, p. 6761.

30. H. Gao, C.-H. Chiu, and J. Lee: Int. J. Solids Struct., 1992, vol. 29, pp. 2471-92.

31. J. Hay and B. Crawford: J. Mater. Res., 2011, vol. 26, pp. 727-38.

32. H. Li and J.J. Vlassak: J. Mater. Res., 2009, vol. 24, pp. 1114-26.

33. Z. Hashin and S. Shtrikman: J. Mech. Phys. Solids, 1963, vol. 11, pp. $127-40$.

34. I. McCue, B. Gaskey, B. Crawford, and J. Erlebacher: Appl. Phys. Lett., 2016, vol. 109, p. 231901.

35. A. Misra, J.P. Hirth, and R.G. Hoagland: Acta Mater., 2005, vol. 53 , pp. 4817-24.

36. J.A. El-Awady: Nat. Commun., 2015, vol. 6, p. 5926.

37. M.F. Ashby: Philos. Mag. A J. Theor. Exp. Appl. Phys., 1970, vol. 21 , pp. $399-424$. 
38. A. Bolshakov and G.M. Pharr: J. Mater. Res., 1998, vol. 13, pp. 1049-58.

39. L. Lin, L. Delaey, O. Van Der Biest, and P. Wollants: Scr. Mater., 1996, vol. 34, pp. 1411-16.

40. S. Torquato: Random Heterogeneous Materials, Springer, New York, 2002, vol. 16

41. A. Fartash, E.E. Fullerton, I.K. Schuller, S.E. Bobbin, J.W. Wagner, R.C. Cammarata, S. Kumar, and M. Grimsditch: Phys. Rev. B, 1991, vol. 44, pp. 13760-63.

42. J.A. Bell, W.R. Bennett, R. Zanoni, G.I. Stegeman, C.M. Falco, and C.T. Seaton: Solid State Commun., 1987, vol. 64, pp. 1339-42.

43. A. Kueny, M. Grimsditch, K. Miyano, I. Banerjee, C.M. Falco, and I.K. Schuller: Phys. Rev. Lett., 1982, vol. 48, pp. 166-70.

44. S.A. Skirlo and M.J. Demkowicz: Appl. Phys. Lett., 2013, vol. 103, p. 171908.

45. K.J. Hemker and W.D. Nix: Nat. Mater., 2008, vol. 7, pp. 97-98.

46. W.D. Nix, J.R. Greer, G. Feng, and E.T. Lilleodden: Thin Solid Films, 2007, vol. 515, pp. 3152-57.

47. A.F. Bower, N.A. Fleck, A. Needleman, and N. Ogbonna: Proc. R. Soc. A Math. Phys. Eng. Sci., 1993, vol. 441, pp. 97-124.

48. D. Tabor: Proc. R. Soc. A Math. Phys. Eng. Sci., 1948, vol. 192, pp. $247-74$.

49. D. Tabor: Rev. Phys. Technol., 1970, vol. 1, pp. 145-79.

50. Y. Cui, B. Derby, N. Li, N.A. Mara, and A. Misra: Mater. Res. Lett., 2018, vol. 6, pp. 184-90.

51. F.F. Csikor, C. Motz, D. Weygand, M. Zaiser, and S. Zapperi: Science, 2007, vol. 318, pp. 251-4.

52. A. Argon: Strengthening Mechanisms in Crystal Plasticity, Oxford University Press, Oxford, 2007.

53. S.H. Oh, M. Legros, D. Kiener, and G. Dehm: Nat. Mater., 2009, vol. 8, pp. 95-100.

54. F. Sansoz, K. Lu, T. Zhu, and A. Misra: MRS Bull., 2016, vol. 41, pp. $292-7$

55. I.A. Ovid'ko, R.Z. Valiev, and Y.T. Zhu: Prog. Mater. Sci., 2018, vol. 94, pp. 462-540.

56. A.D. Rollett and U.F. Kocks: Solid State Phenom., 1993, vols. $35-36$, pp. $1-18$.

57. N.A. Mara, D. Bhattacharyya, J.P. Hirth, P. Dickerson, and A. Misra: Appl. Phys. Lett., 2010, vol. 97, p. 021909.
58. Y.Y. Lu, R. Kotoka, J.P. Ligda, B.B. Cao, S.N. Yarmolenko, B.E. Schuster, and Q. Wei: Acta Mater., 2014, vol. 63, pp. 216-31.

59. A. Junkaew, B. Ham, X. Zhang, and R. Arróyave: Comput. Mater. Sci., 2015, vol. 108, pp. 212-25.

60. E. Frutos, M. Callisti, M. Karlik, and T. Polcar: Mater. Sci. Eng. A, 2015, vol. 632, pp. 137-46.

61. B. Derby, Y. Cui, J.K. Baldwin, and A. Misra: Thin Solid Films, 2018, vol. 647 , pp. $50-56$.

62. F.T.N. Vüllers and R. Spolenak: Acta Mater., 2015, vol. 99, pp. 213-27.

63. I. McCue, S. Ryan, K. Hemker, X. Xu, N. Li, M. Chen, and J. Erlebacher: Adv. Eng. Mater., 2016, vol. 18, pp. 46-50.

64. M. Ortiz, Y. Leroy, and A. Needleman: Comput. Methods Appl. Mech. Eng., 1987, vol. 61, pp. 189-214.

65. A. Needleman: J. Appl. Mech., 1987, vol. 54, p. 525.

66. J. Pan, M. Saje, and A. Needleman: Int. J. Fract., 1983, vol. 21, pp. 261-78.

67. V. Tvergaard and A. Needleman: Acta Metall., 1984, vol. 32, pp. 157-69.

68. K. Sitarama Raju, V. Subramanya Sarma, A. Kauffmann, Z. Hegedüs, J. Gubicza, M. Peterlechner, J. Freudenberger, and G. Wilde: Acta Mater., 2013, vol. 61, pp. 228-38.

69. Y. Wang, M. Chen, F. Zhou, and E. Ma: Nature, 2002, vol. 419 , pp. 912-15.

70. X. Wu, M. Yang, F. Yuan, G. Wu, Y. Wei, X. Huang, and Y. Zhu: Proc. Natl. Acad. Sci., 2015, vol. 112, pp. 14501-05.

71. X. Wu and Y. Zhu: Mater. Res. Lett., 2017, vol. 5, pp. 527-32.

72. Y. Zhu, R.Z. Valiev, T.G. Langdon, N. Tsuji, and K. Lu: MRS Bull., 2010, vol. 35, pp. 977-81.

73. C. Fan, R.T. Ott, and T.C. Hufnagel: Appl. Phys. Lett., 2002, vol. 81 , pp. 1020-22.

74. D.C. Hofmann, J.-Y. Suh, A. Wiest, G. Duan, M.-L. Lind, M.D. Demetriou, and W.L. Johnson: Nature, 2008, vol. 451, pp. $1085-89$.

Publisher's Note Springer Nature remains neutral with regard to jurisdictional claims in published maps and institutional affiliations. 